\title{
Greater Refill Adherence to Adalimumab Therapy for Patients Using Specialty Versus Retail Pharmacies
}

Yifei Liu $\cdot$ Mei Yang $\cdot$ Jingdong Chao $\cdot$ Parvez M. Mulani

Received: June 17, 2010 / Published online: July 19, 2010

(c) The Author(s) 2010. This article is published with open access at Springerlink.com

\section{ABSTRACT}

Introduction: Retail pharmacies provide regular prescription drugs and some specialty prescription drugs, whereas specialty pharmacies focus on distributing specialty prescription drugs, including tumor necrosis factor (TNF) antagonists. It is unknown whether pharmacy type impacts patients' adherence to anti-TNF therapy. The relationship between pharmacy type (specialty vs. retail) and refill adherence to therapy with the TNF antagonist adalimumab was examined. Methods: This was a retrospective analysis of dispensing records of patients in the United States who were prescribed a TNF antagonist (adalimumab $40 \mathrm{mg}$ per 0.8-mL injection) during a dispensation period from January 2003 to August 2009. Patients treated with adalimumab were included in the analysis regardless of diagnosis.

Yifei Liu $(\bowtie)$

Assistant Professor, Division of Pharmacy Practice and Administration, 4248 Health Sciences Building, School of Pharmacy, The University of Missouri-Kansas City, Kansas City, MO 64108, USA. Email: liuyif@umkc.edu

Mei Yang · Jingdong Chao · Parvez M. Mulani Global Health Economics and Outcomes Research, Abbott Laboratories, Abbott Park, IL, USA
For each patient, medication refill adherence (MRA) was calculated as total days of supply divided by total number of days evaluated, multiplied by 100 . A regression analysis was conducted in which the dependent variable was MRA and the independent variables included pharmacy type (specialty vs. retail pharmacy), reimbursement/payment type, copayment/ payment amount per prescription, age, sex, ethnicity, and annual income. Results: Of the 86,079 patients included, $70 \%$ obtained the medication from a specialty pharmacy, 92\% were members of Blue Cross and Blue Shield plans, $67 \%$ were women, and $81 \%$ were white. The average MRA was 84 , and the average age was 52 years. Significant predictors $(P<0.05)$ of MRA included pharmacy type, reimbursement/ payment type, copayment/payment amount per prescription, age, sex, and ethnicity; and pharmacy type was the strongest predictor. When other independent variables were controlled for, MRA was $16 \%$ less for patients who used a retail pharmacy vs. patients who used a specialty pharmacy. Conclusion: Patients who used a specialty pharmacy to fulfill prescriptions for a TNF antagonist had a greater refill adherence than did patients who used a retail pharmacy. 
Keywords: adalimumab; medication refill adherence; retail pharmacy; specialty pharmacy

\section{INTRODUCTION}

In the United States, there are different approaches to classify a pharmacy in the ambulatory care setting. For example, for pharmacy ownership, a pharmacy can be categorized primarily as a chain pharmacy, an independent pharmacy, or an outpatient pharmacy of a health institution. ${ }^{1}$ In addition, from the perspective of drug inventory or distribution, a pharmacy can be classified mainly as a retail pharmacy (a traditional pharmacy), which provides general prescription drugs and some specialty prescription drugs, or a specialty pharmacy, which specializes in the distribution of specialty prescription drugs. ${ }^{2}$ These specialty medications include high-cost injectable, infused, oral, and inhaled therapies for conditions that require complex care, such as rheumatoid arthritis, multiple sclerosis, cancer, and hemophilia. ${ }^{3}$

In 2004 , less than $3 \%$ of private health plan members used specialty medications. ${ }^{3}$ However, because of their high costs, specialty medications represented an estimated $\$ 35$ billion market in 2006, which accounted for $16 \%$ of expenditures on prescription drugs in 2006., ${ }^{4,5}$ According to Aon Consulting's Spring 2009 Health Care Trend Survey, the rate of increase in specialty drug costs was forecasted to be $13.2 \%$ per year, which was approximately $4 \%$ greater than the rate for general drug costs. ${ }^{6}$ Recently, pharmacy benefit management companies and specialty pharmacies have been consolidating. ${ }^{7,8}$ For instance, pharmacy benefit management companies have acquired or allied with existing specialty pharmacies or created their own specialty pharmacies from mail-order facilities.
Tumor necrosis factor (TNF) antagonists are a therapeutic class of specialty prescription drugs for the treatment of autoimmune disorders, such as rheumatoid arthritis, psoriatic arthritis, ankylosing spondylitis, and Crohn's disease. ${ }^{9}$ In the ambulatory care setting in the United States, the most frequently prescribed TNF antagonists are etanercept, infliximab, adalimumab, and certolizumab pegol. Patients prescribed these medications can obtain them through a retail pharmacy or a specialty pharmacy. Previous research showed that nonadherence to anti-TNF therapy is associated with poor outcomes. ${ }^{10}$ Thus, it is important to identify predictors of adherence that can potentially be modified to better design strategies for improving patients' adherence.

Medication adherence is defined as "the extent to which a patient acts in accordance with the prescribed interval and dose of a dosing regimen." 11 Inadequate adherence may result in negative health outcomes, such as increased morbidity and mortality. ${ }^{12,13}$ Adherence may be affected by myriad factors related to the cost, the dosage form, the medical condition, the patient, the healthcare provider, the relationship between the patient and the healthcare provider, or the environment in which the medication is used. ${ }^{13-15}$ A systems approach to predicting patients' adherence behaviors considers how the environment, including healthcare delivery systems, affects patients' adherence. ${ }^{16}$ The pharmacy or pharmaceutical care service are components of the healthcare system that can have an impact on patients' adherence. ${ }^{17-19}$

The research in system-related factors is limited and not conclusive. Two studies explored the relationship between pharmacy type and medication adherence to therapy with specialty medications. One study compared patients with hepatitis $\mathrm{C}$ who used a specialty pharmacy vs. a retail pharmacy, and found no difference in therapy completion rates. ${ }^{20}$ Another study 
revealed that patients with multiple sclerosis or inflammatory conditions who used a specific specialty pharmacy had lower rates of therapy discontinuation than those using a retail pharmacy or another specialty pharmacy. ${ }^{21}$ Specialty pharmacies may be better equipped to provide specialty medications compared with retail pharmacies. For example, retail pharmacies may have limited capacity for storage and delivery, lack of direct access to payers, unavailability of pharmacists beyond regular store hours, and limited supplies of accessories (eg, needle, syringe, alcohol swab, etc). ${ }^{2}$ In this study, the relationship between two types of pharmacies (specialty vs. retail) and patients' refill adherence to therapy with a TNF antagonist was examined. It was hypothesized that patients who obtained the TNF antagonist from a specialty pharmacy would have a greater medication refill adherence (MRA) than those who obtained the drug from a retail pharmacy.

\section{METHODS}

\section{Design and Original Data}

This study was a retrospective analysis of dispensing records of patients in the United States who were prescribed a TNF antagonist (adalimumab $40 \mathrm{mg}$ per $0.8-\mathrm{mL}$ injection) from January 11, 2003, to August 13, 2009. Adalimumab is approved to treat rheumatoid arthritis, juvenile idiopathic arthritis, psoriatic arthritis, chronic plaque psoriasis, ankylosing spondylitis, and Crohn's disease. ${ }^{22}$

The data were collected by Wolters Kluwer Pharma Solutions (Phoenix, AZ, USA) from pharmacy terminals in deidentified format in compliance with the Health Insurance Portability and Accountability Act of 1996. The patients and their dispensed prescriptions were longitudinally linked in the data. Wolters Kluwer
Health provided a database as well as a codebook that interpreted the variables. The database had $1,291,958$ adalimumab prescription dispensing records, with each record corresponding to a prescription. Each record included variables such as the patient identification number; prescription drug name; United States national drug code; ${ }^{23}$ the dispensing date of the prescription; days of supply for the prescription; pharmacy type (specialty or retail pharmacy); reimbursement or payment type; the copayment or payment amount; and the patient's birth year, sex, ethnicity, and annual income. Adalimumab prescriptions were identified through the United States national drug codes 00074-3799-02, 00074-4339-02, 00074-4339-06, 00074-4399-07, 00074-9374-02, 54569-5524-00, and 54868-4822-00. The data were reviewed and analyzed by a researcher at a university. The study was exempt from the review of the university institutional review board because the institutional review board determined that the data were deidentified.

\section{Measures and Restructured Data}

Various measures have been developed to estimate patients' actual medication adherence, known as refill adherence, from administrative pharmacy data, depending on the availability of data variables. ${ }^{24}$ The measures include continuous single-interval measure of medication availability, continuous measure of medication acquisition, compliance rate, days-betweenfills adherence rate, continuous measure of medication gaps, continuous multiple-interval measure of oversupply, medication possession ratio, refill compliance rate, MRA, and proportion of days covered. After comparing these measures, Hess et al. ${ }^{24}$ recommended the use of MRA as the preferred measure because MRA provided the closest estimation of the direct observed 
adherence. MRA equals total days of supply divided by the number of days evaluated, then multiplied by 100 , which is a percentage and is capped at 100. Numerically, MRA ranges from 0 to 100; 0 indicates that the patient did not comply at all with the refill instructions on the prescription and 100 indicates that the patient was $100 \%$ adherent to the refill instructions.

In this study, MRA was used to measure patients' refill adherence, and patients who had only one prescription or only had prescriptions on one dispensation date were excluded, because the intention of the study was to examine the maintenance population. For each patient, the number of days evaluated was the number of days between the first and the last dispensation dates. Total days of supply were the sum of days of supply for each prescription, except the prescription on the last dispensation date. In addition, the total days of supply per prescription per patient, and the copayment or payment amount per prescription per patient were calculated.

The database was restructured using the following steps: (1) patients who had only one prescription or only had all prescriptions on one dispensation date were excluded; (2) patients who obtained the drug from more than one type of pharmacy, or who used more than one mechanism to reimburse or pay the prescription were excluded, because the aim was to identify a single value for patient's pharmacy type, or their reimbursement/payment type; and (3) the database was organized such that each patient identification number (ie, each patient) was associated with a single case. Figure 1 displays the process of study sample selection.

In the restructured database, variables for each patient included the number of prescriptions; the number of days evaluated; total days of supply; total days of supply per prescription; MRA; pharmacy type (specialty or retail pharmacy);
Figure 1. Process of study sample selection.

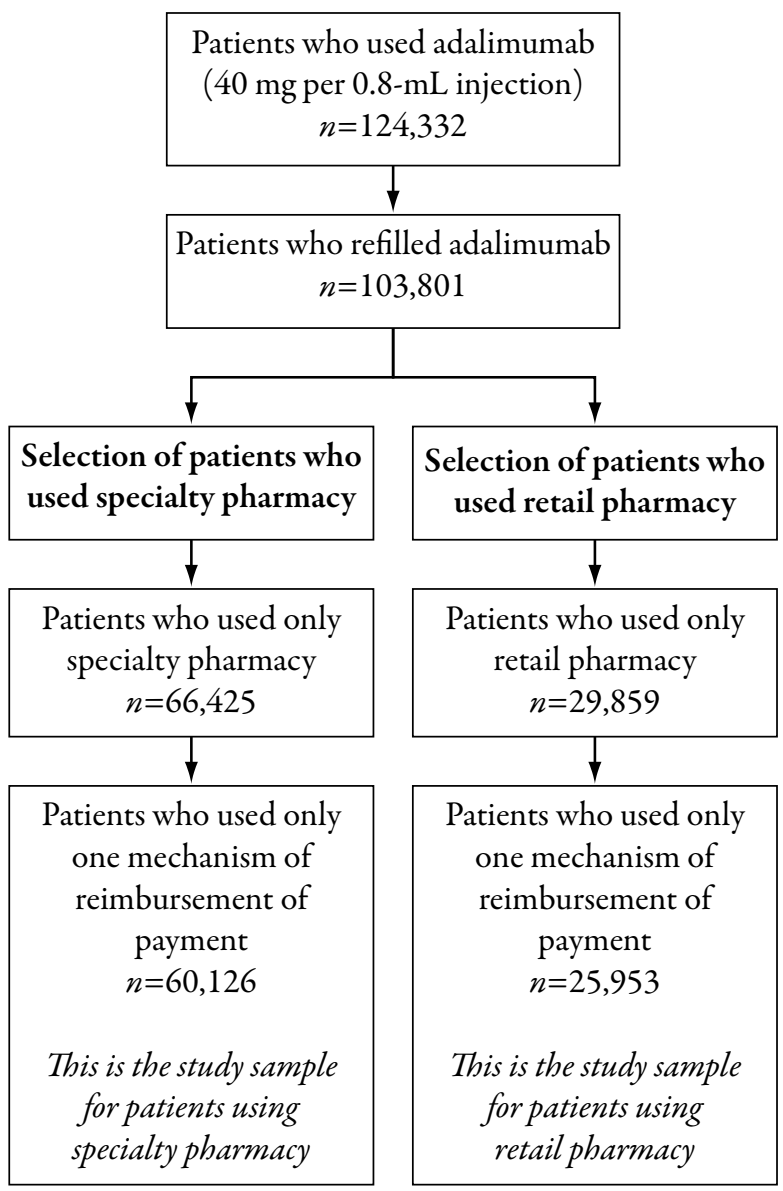

reimbursement or payment type (Blue Cross and Blue Shield plan members, members of federal insurance programs, or cash payers without insurance); the copayment or payment amount per prescription; and the patient's age, sex, ethnicity, and annual income.

\section{Data Analyses}

Descriptive statistics or frequency analyses were performed for each variable, and the characteristics of patients between two types of pharmacy were compared. Student's $t$-tests were used to compare the number of prescriptions, total days of supply, MRA, the copayment/ payment amount per prescription, and age between the two groups. Chi-square tests were 
used to compare reimbursement/payment type, sex, ethnicity, and annual income.

Bivariate correlations between variables were examined. A linear regression analysis using ordinary least squares was also conducted, in which the dependent variable was MRA and the independent variables included pharmacy type, reimbursement or payment type, copayment or payment amount per prescription, age, sex, ethnicity, and annual income. An independent categorical variable was coded as a dummy variable or a set of dummy variables and the group with the highest frequency of patients was set as the reference group. For the dependent variable, the percentage of MRA (which ranged from 0 to 100) in the regression was used instead of its actual value (which ranged from 0 to 1 ). Collinearity was assessed by variance inflation factor, and it was not an issue. ${ }^{25}$ The Statistical Analysis System version 9.1 (SAS $^{\circledR}$, Cary, NC, USA) was used to restructure the original data and Statistical Package for Social Science version 16.0 (SPSS $^{\circledR}$, Chicago, IL, USA) was used to analyze the restructured data.

\section{RESULTS}

Of 124,322 patients, 86,079 met the selection criteria and were included in the analysis (Figure 1). Table 1 lists the characteristics of these patients. Seventy percent of patients obtained the medication from a specialty pharmacy. There was a wide range in terms of the patients' ages (1-80 years) and copayment/payment amounts per prescription $(\$ 0-\$ 27,840.21)$. The largest copayment/payment amount, $\$ 27,840.21$, might be an outlier. Compared with patients using a retail pharmacy, those who used a specialty pharmacy had greater average values in total days of supply (379.39 vs. 236.03), days of supply per prescription (41.39 vs. 29.89),
Table 1. Characteristics of patients identified.

\begin{tabular}{|c|c|}
\hline Variables & Values \\
\hline \multicolumn{2}{|l|}{ Number of prescriptions } \\
\hline Mean $\pm S D$ & $10.16 \pm 12.61$ \\
\hline Median & 6 \\
\hline Range & $1-113$ \\
\hline Total ${ }^{*}, n$ & 86,079 \\
\hline \multicolumn{2}{|l|}{ Total days of supply } \\
\hline Mean $\pm S D$ & $336.17 \pm 391.72$ \\
\hline Median & 196 \\
\hline Range & $1-3694$ \\
\hline Total $^{*}, n$ & 86,079 \\
\hline \multicolumn{2}{|l|}{ Total days of supply per prescription } \\
\hline Mean \pm SD & $37.92 \pm 20.48$ \\
\hline Median & 28 \\
\hline Range & $1-322.5$ \\
\hline Total $^{*}, n$ & 86,079 \\
\hline \multicolumn{2}{|l|}{ MRA } \\
\hline Mean $\pm S D, \%$ & $84.02 \pm 22.03$ \\
\hline Median, \% & 95.45 \\
\hline Range, \% & $0.43-100$ \\
\hline Total ${ }^{*}, n$ & 86,079 \\
\hline \multicolumn{2}{|l|}{ Pharmacy type, $n(\%)$} \\
\hline Specialty pharmacy & $60,126(69.8)$ \\
\hline Retail pharmacy & $25,953(30.2)$ \\
\hline Total $^{*}$ & $86,079(100)$ \\
\hline \multicolumn{2}{|l|}{ Reimbursement/payment type, $n$ (\%) } \\
\hline Blue Cross and Blue Shield plans & $79,062(91.8)$ \\
\hline Federal programs $t$ & $4122(4.8)$ \\
\hline Cash payers without insurance & $2895(3.4)$ \\
\hline Total $^{*}$ & $86,079(100)$ \\
\hline \multicolumn{2}{|c|}{ Copayment/payment amount per prescription } \\
\hline Mean $\pm S D, \$$ & $105.19 \pm 352.41$ \\
\hline Median, \$ & 29.63 \\
\hline Range, \$ & $0-27,840.21$ \\
\hline Total $^{*}, n$ & 85,536 \\
\hline \multicolumn{2}{|l|}{$\overline{\text { Age }}$} \\
\hline Mean $\pm S D$, years & $52.33 \pm 14.74$ \\
\hline Median, years & 53 \\
\hline Range, years & $1-80$ \\
\hline Total $^{*}, n$ & 83,055 \\
\hline \multicolumn{2}{|l|}{ Sex, $n(\%)$} \\
\hline Female & $55,474(67.1)$ \\
\hline Male & $27,205(32.9)$ \\
\hline Total ${ }^{*}$ & $82,680(100)$ \\
\hline \multicolumn{2}{|l|}{ Ethnicity, $n(\%)$} \\
\hline White & $34,519(81.2)$ \\
\hline Hispanic & $2214(5.2)$ \\
\hline Black & $1696(4.0)$ \\
\hline Asian & $401(0.9)$ \\
\hline Other & $3699(8.7)$ \\
\hline Total ${ }^{*}$ & $42,529(100)$ \\
\hline \multicolumn{2}{|l|}{ Annual income, $n(\%)$} \\
\hline$<\$ 30,000$ & $4392(10.3)$ \\
\hline$\$ 30,000-\$ 49,999$ & $11,369(26.7)$ \\
\hline$\$ 50,000-\$ 74,999$ & $12,110(28.5)$ \\
\hline$>\$ 74,999$ & $14,658(34.5)$ \\
\hline Total ${ }^{*}$ & $42,529(100)$ \\
\hline
\end{tabular}

*Total numbers vary because of missing values.

†US federal programs included Medicare, veteran administration plan, and other federal programs.

$\mathrm{MRA}=$ medication refill adherence. 
Table 2. Comparison of patients using retail pharmacy vs. specialty pharmacy.

\begin{tabular}{|c|c|c|}
\hline Variables* & Patients using retail pharmacy & Patients using specialty pharmacy \\
\hline \multicolumn{3}{|l|}{ Number of prescriptions } \\
\hline Mean \pm SD & $8.22 \pm 9.72$ & $10.99 \pm 13.58$ \\
\hline Median & 4 & 6 \\
\hline Range & $1-104$ & $1-113$ \\
\hline Totalt, $n$ & 25,953 & 60,126 \\
\hline \multicolumn{3}{|l|}{ Total days of supply } \\
\hline Mean $\pm S D$ & $236.03 \pm 276.12$ & $379.39 \pm 424.93$ \\
\hline Median & 140 & 252 \\
\hline Range & $1-2340$ & $1-3694$ \\
\hline Totalt, $n$ & 25,953 & 60,126 \\
\hline \multicolumn{3}{|l|}{ Total days of supply per prescription } \\
\hline Mean $\pm S D$ & $29.89 \pm 12.55$ & $41.39 \pm 22.19$ \\
\hline Median & 28 & 28 \\
\hline Range & $1-322.5$ & $1-168$ \\
\hline Totalt, $n$ & 25,953 & 60,126 \\
\hline \multicolumn{3}{|l|}{ MRA } \\
\hline Mean \pm SD, $\%$ & $72.61 \pm 25.71$ & $88.94 \pm 18.14$ \\
\hline Median, \% & 78.87 & 100 \\
\hline Range, \% & $0.43-100$ & $1.88-100$ \\
\hline Total,$+ n$ & 25,953 & 60,126 \\
\hline \multicolumn{3}{|l|}{ Reimbursement/payment type, $n(\%)$} \\
\hline Blue Cross and Blue Shield plans & $21,765(83.9)$ & $57,297(95.3)$ \\
\hline Federal programs $\ddagger$ & $1860(7.1)$ & $2262(3.8)$ \\
\hline Cash payers without insurance & $2328(9.0)$ & $567(0.9)$ \\
\hline Total $t$ & $25,953(100)$ & $60,126(100)$ \\
\hline \multicolumn{3}{|c|}{ Copayment/payment amount per prescription } \\
\hline Mean \pm SD, \$ & $82.99 \pm 239.27$ & $114.78 \pm 390.87$ \\
\hline Median, \$ & 21.67 & 30 \\
\hline Range, \$ & $0-5448.99$ & $0-27,840.21$ \\
\hline Totalt, $n$ & 25,785 & 59,751 \\
\hline \multicolumn{3}{|l|}{ Age } \\
\hline Mean $\pm S D$, years & $54.40 \pm 14.75$ & $51.41 \pm 14.65$ \\
\hline Median, years & 55 & 53 \\
\hline Range, years & $4-80$ & $1-80$ \\
\hline Total,$+ n$ & 25,578 & 57,477 \\
\hline \multicolumn{3}{|l|}{ Sex, $n(\%)$} \\
\hline Female & $17,868(70.2)$ & $37,607(65.7)$ \\
\hline Male & $7593(29.8)$ & $19,612(34.3)$ \\
\hline Total $\dagger$ & $25,461(100)$ & $57,219(100)$ \\
\hline \multicolumn{3}{|l|}{ Ethnicity, $n(\%)$} \\
\hline White & $10,028(81.0)$ & $24,491(81.2)$ \\
\hline Hispanic & $641(5.2)$ & $1573(5.2)$ \\
\hline Black & $537(4.3)$ & $1159(3.8)$ \\
\hline Asian & $121(1.0)$ & $280(0.9)$ \\
\hline Other & $1059(8.5)$ & $2640(8.8)$ \\
\hline Total $\dagger$ & $12,386(100)$ & $30,143(100)$ \\
\hline \multicolumn{3}{|l|}{ Annual income, $n(\%)$} \\
\hline$<\$ 30,000$ & $1495(12.1)$ & $2897(9.6)$ \\
\hline$\$ 30,000-\$ 49,999$ & $3444(27.8)$ & $7925(26.3)$ \\
\hline$\$ 50,000-\$ 74,999$ & $3333(26.9)$ & $8,777(29.1)$ \\
\hline$>\$ 74,999$ & $4114(33.2)$ & $10,544(35.0)$ \\
\hline Total $\dagger$ & $12,386(100)$ & $30,143(100)$ \\
\hline
\end{tabular}

${ }^{*}$ Comparisons of all variables between two groups were significant at the 0.01 level. Student's $t$-tests were used to compare number of prescriptions, total days of supply, total days of supply per prescription, MRA, copayment/payment amount per prescription, and age. Chi-square testes were used to compare the other variables.

†Total numbers vary because of missing values.

‡US federal programs included Medicare, veteran administration plan, and other federal programs.

$\mathrm{MRA}=$ medication refill adherence. 
Table 3. Regression model of medication refill adherence.

\begin{tabular}{|c|c|c|}
\hline Regression model & \multicolumn{2}{|c|}{$\operatorname{MRA}\left(n=41,841^{*}\right)$} \\
\hline$\overline{\text { Adjusted } \mathrm{R}^{2}}$ & \multicolumn{2}{|c|}{0.12} \\
\hline Df & \multicolumn{2}{|c|}{13} \\
\hline $\mathrm{F}$ & \multicolumn{2}{|c|}{$433.06+$} \\
\hline Independent variables & $\begin{array}{l}\text { Unstandardized } \\
\text { beta }\end{array}$ & $\begin{array}{l}\text { Standardized } \\
\text { beta }\end{array}$ \\
\hline \multicolumn{3}{|l|}{ Pharmacy type $\neq$} \\
\hline Retail pharmacy & $-16.38 \dagger$ & $-0.34 \dagger$ \\
\hline \multicolumn{3}{|l|}{ Reimbursement/payment type $\S$} \\
\hline Federal programs & $0.93 \diamond$ & $0.01 \diamond$ \\
\hline Cash payers without insurance & -1.28 & -0.01 \\
\hline $\begin{array}{l}\text { Copayment/payment amount } \\
\text { per prescription }\end{array}$ & $-0.00 \diamond$ & $-0.01 \diamond$ \\
\hline Age & $0.06 \dagger$ & $0.04 \dagger$ \\
\hline Sex (male) & $0.95+$ & $0.02 \dagger$ \\
\hline \multicolumn{3}{|l|}{ Ethnicity\# } \\
\hline Hispanic & $-1.63 \dagger$ & $-0.02 \dagger$ \\
\hline Black & $-2.09+$ & $-0.02 \dagger$ \\
\hline Asian & 1.49 & 0.01 \\
\hline Other & -0.04 & -0.00 \\
\hline \multicolumn{3}{|l|}{ Annual income $\square$} \\
\hline$<\$ 30,000$ & -0.09 & -0.00 \\
\hline$\$ 30,000-\$ 49,999$ & -0.24 & -0.01 \\
\hline$\$ 50,000-\$ 74,999$ & 0.16 & 0.00 \\
\hline
\end{tabular}

${ }^{*} n=41,841$ owing to missing values.

†Significant at the 0.01 level.

$\neq$ The reference group is specialty pharmacy.

$\S$ The reference group is Blue Cross and Blue Shield plans.

$\triangle$ Significant at the 0.05 level.

The reference group is female.

\#The reference group is white.

$\square$ The reference group is $>\$ 74,999$.

$\mathrm{Df}=$ degrees of freedom; MRA=medication refill adherence.

and MRA ( $88.94 \%$ vs. $72.61 \%$; Student's $t$-tests, $P<0.01$; Table 2).

Results of the regression analysis are presented in Table 3. Significant predictors $(P<0.05)$ of MRA included pharmacy type, reimbursement/ payment type, copayment/payment amount per prescription, age, sex, and ethnicity. Pharmacy type was the strongest significant predictor for MRA. Copayment/payment amount per prescription and the patient's age were also significant predictors, but the association was not strong. Compared with patients who used a specialty pharmacy, patients who used a retail pharmacy had a 16\% lesser MRA, controlling for the other independent variables. When the other independent variables were controlled for, patients in federal insurance programs had a $1 \%$ greater MRA than did patients who were Blue Cross and Blue Shield plan members. Also, male patients had a $1 \%$ greater MRA than did female patients. Compared with white patients, Hispanic patients and black patients had a $2 \%$ lesser MRA.

\section{DISCUSSION}

To the authors' knowledge, and based on a review of the literature, this study represents the first effort to examine the impact of two pharmacy types (specialty vs. retail pharmacy) as system factors on patients' adherence to therapy with a TNF antagonist. As patients' adherence can be affected by many factors ${ }^{12-14}$ and administrative pharmacy data usually contain a small subset of these factors, the variables from administrative data may only explain a limited amount of variance in refill adherence. For instance, Schectman et al. ${ }^{26}$ used pharmacy claims data to examine the impact of demographic and prescription characteristics on refill adherence, and the regression model explained $6.8 \%$ of the variance in refill adherence. In this study, the regression model explained $12 \%$ of variance in MRA. In particular, medication source contributed the most to explaining the variance of MRA and was the strongest predictor of MRA (standardized beta $=-0.34, P<0.01)$, indicating that environmental factors (such as pharmacy type) play an important role in patients' adherence.

The primary finding of the present study was that patients who used a specialty pharmacy had a refill adherence $16 \%$ greater than those who used a retail pharmacy. Although it was predicted that specialty pharmacies would be 
more strongly associated with refill adherence than retail pharmacies, there could be reasons to support the opposite hypothesis as well. For example, a specialty pharmacy frequently uses mail order to deliver medications, whereas a retail pharmacy often has in-store sales of medications during patient visits. One might potentially predict that patients' adherence at a retail pharmacy would be greater because a face-to-face encounter may better foster the patient-pharmacist relationship and improve patients' adherence. Nonetheless, the study's hypothesis was well supported by the regression results, which showed that specialty pharmacies more positively influenced patients' refill adherence than did retail pharmacies. Thus, this study demonstrated the value of specialty pharmacies in terms of medication adherence.

In managed care, ensuring proper usage of specialty medications has presented a challenge to third-party payers. On one hand, owing to the high cost, nearly half of payers had restrictions on the distribution of specialty medications. ${ }^{27}$ On the other hand, owing to the complex care associated with specialty medications, payers have requested relevant pharmaceutical care services to assist patients with usage, especially from specialty pharmacies. ${ }^{8}$ Therefore, third-party payers have increasingly asked pharmaceutical manufacturers and specialty pharmacies for positive outcomes to justify providing these regimens and related services. ${ }^{8}$

Whereas pharmaceutical manufacturers are responsible for demonstrating the outcomes of specialty medications, specialty pharmacies need to demonstrate the outcomes associated with pharmaceutical care services, such as proactive refill management and medication adherence monitoring. In proactive refill management, reminder mailings, calls, or emails are sent to patients prior to the refill date; in medication adherence monitoring, pharmacists can contact the patients in a timely fashion if inadequate adherence is noticed. The data from the present study suggests that specialty pharmacies should be preferred over retail pharmacies for dispensing specialty medications. In addition, consistent with previous findings, ${ }^{13-15}$ it was found that reimbursement/payment type and patients' sex and ethnicity affected medication adherence. This suggests that pharmaceutical care services, like proactive refill management, should be targeted more toward patients who are women, black, or Hispanic. It can be hypothesized that if specialty pharmacies increased the frequency of refill reminders to these groups, adherence might increase.

Usually, individual patients do not have choice of specialty pharmacy vs. retail pharmacy. The choice is generally made by insurance companies. Given that patients had a $16 \%$ greater MRA at a specialty pharmacy than a retail pharmacy, insurance companies should shift distribution of biologics from retail pharmacies to specialty pharmacies. Also, manufacturers should reevaluate the efficiency of delivering TNF antagonists and make appropriate adjustments to their strategies of managing marketing channels. The term marketing channel refers to how a product or service is sold or delivered from the producer to consumers ${ }^{28}$ and specialty and retail pharmacies represent two marketing channels used by pharmaceutical manufacturers to distribute specialty medications. Manufacturers might reconsider the current approach and shift the emphasis to specialty pharmacies. Shifting to specialty pharmacies may also reduce the number of intermediaries between manufacturers and patients, improving inventory management. 


\section{Limitations}

There were three limitations in this study. First, data were taken from dispensing records, and the information for each record or patient was limited. Data such as the patient's medical condition, the severity of the condition, the use of other medications, forgetfulness, and the relationship between patients and healthcare providers were not available in the database. These factors may influence medical adherence. The bias from not evaluating these factors was considered nondifferential to the types of pharmacy and thus less likely to have an impact on the conclusion of the study. Second, refill adherence was used to estimate the actual adherence, which may not truly reflect the actual adherence. It was assumed that patients consumed the medication as prescribed after they obtained the medication on the day of dispensation. ${ }^{24}$ Some patients might not use the medication as prescribed after they obtained the medication. However, this misclassification of adherence was considered to be not related to pharmacy type, and, thus, it is less likely to have affected the conclusions of the study. Third, the majority of the samples were from Blue Cross and Blue Shield plans. The validation of the conclusion of the present study in other insured populations would increase the generalizability of the findings. Furthermore, future research can build on the results of this study by assessing the role of pharmacy type in patients' adherence to other specialty medications. Whereas the present study involved retrospective design and secondary data analysis, other study designs (eg, prospective cohort design) and other techniques (eg, surveys or interviews) should be explored.

In conclusion, patients who used a specialty pharmacy to obtain a TNF antagonist had greater refill adherence than patients who used a retail pharmacy. Specialty pharmacies may be considered the preferred distribution channel for TNF antagonists.

\section{ACKNOWLEDGMENTS}

This work was funded by Abbott Laboratories, Abbott Park, IL, United States. Editorial assistance in the preparation of this manuscript was provided by Arbor Communications, Inc., and Michael A. Nissen, ELS, of Abbott Laboratories and was funded by Abbott Laboratories. M.Y., J.C., and P.M.M. are employees of Abbott Laboratories and hold stock and stock options in Abbott Laboratories. Y.L. has no conflicts of interest to declare.

Open Access. This article is distributed under the terms of the Creative Commons Attribution Noncommercial License which permits any noncommercial use, distribution, and reproduction in any medium, provided the original author(s) and source are credited.

\section{REFERENCES}

1. Mott DA, Doucette WR, Gaither CA, Kreling DH, Pedersen CA, Schommer JC. Pharmacist participation in the workforce: 1990, 2000, and 2004. J Am Pharm Assoc. 2006;46:322-330.

2. Suchanek D. The rise and role of specialty pharmacy. Biotechnol Healthcare. 2005:31-35.

3. Fontanez C, McDermott R, Whitehead D. 2004 Specialty Pharmacy Management Guide \& Trend Report. St. Louis, MO: CuraScript Pharmacy, 2005. Available at: http://www.curascript.com/bin_web/ documents/SRxTrendReport04.pdf. Last accessed March 22, 2010.

4. Knowledge Source Inc. Specialty Pharmacies Market Overview 2006. Trumbull, CT: Knowledge Source Inc; 2006.

5. Kaiser Family Foundation. Prescription Drug Trends. Melo Park, CA: Kaiser Family Foundation, 
2008. Available at: http://www.kff.org/rxdrugs/ upload/3057_07.pdf. Last accessed March 22, 2010.

6. Aon Consulting. Spring 2009 Health Care Trend Survey. Chicago, IL: Aon, 2009. Available at: http://www.aon.com/attachments/Spring_2009_ Healthcare.pdf. Last accessed March 22, 2010.

7. Adams KT. Specialty pharmacy at a crossroad. Biotechnol Healthcare. 2005:22-30.

8. Stern D, Reissman D. Specialty pharmacy cost management strategies of private health care payers. J Manag Care Pharm. 2006;12:736-744.

9. Nash PT, Florin TH. Tumour necrosis factor inhibitors. Med J Aust. 2005;183:205-208.

10. Kane SV, Chao J, Mulani PM. Adherence to infliximab maintenance therapy and health care utilization and costs by Crohn's disease patients. Adv Ther. 2009;26:936-946.

11. Cramer JA, Roy A, Burrell A, et al. Medication compliance and persistence: terminology and definitions. Value Health. 2008;11:44-47.

12. Cramer JA. Partial medication compliance: the enigma in poor medical outcomes. Am J Manag Care. 1995;1:167-174.

13. DiMatteo MR, Giordani PJ, Lepper HS, Croghan TW. Patient adherence and medical treatment outcomes: a meta-analysis. Med Care. 2002;40:794811.

14. Vermeire E, Hearnshaw H, Van Royen P, Denekens J. Patient adherence to treatment: three decades of research. A comprehensive review. J Clin Pharm Ther. 2001;26:331-342.

15. Vik SA, Maxwell CJ, Hogan DB. Measurement, correlates, and health outcomes of medication adherence among seniors. Ann Pharmacother. 2004;38:303-312.

16. Leventhal H, Cameron L. Behavioral theories and the problem of compliance. Patient Educ Couns. 1987;10:117-138.

17. Chao J. Improving medication adherence: the role of the health care delivery system and health care providers. J Manag Care Pharm. 2007;13:807-809.

18. Lee JK, Grace KA, Taylor AJ. Effect of a pharmacy care program on medication adherence and persistence, blood pressure, and low density lipoprotein cholesterol: a randomized controlled trial. JAMA. 2006;296:2563-2571.

19. Stockl KM, Shin JS, Gong S, Harada AS, Solow BK, Lew HC. Improving patient self-management of multiple sclerosis through a disease therapy management program. Am J Manag Care. 2010;16:139-144.

20. Cohen SM, Kwasny MJ, Ahn J. Use of specialty care versus standard retail pharmacies for treatment of hepatitis C. Ann Pharmacother. 2009;43:202-209.

21. Express Scripts Inc. Factors predicting patient compliance with specialty drug therapy for multiple sclerosis, inflammatory conditions and hepatitis C. St. Louis, MO: Express Scripts Inc., 2006. Available at: http://www.express-scripts. com/research/studies/pharmacybenefitresearch/ specialtypharmacyservices/docs/factorsPredicting PatientCompliance.pdf. Last accessed May 3, 2010.

22. [no authors] Humira prescribing information. North Chicago, IL: Abbott Laboratories, 2009.

23. FDA. National Drug Code Directory. Available at: http://www.accessdata.fda.gov/scripts/cder/ndc/ default.cfm. Last accessed July 1, 2010.

24. Hess LM, Raebel MA, Conner DA, Malone DC. Measurement of adherence in pharmacy administrative databases: a proposal for standard definitions and preferred measures. Ann Pharmacother. 2006;40:1280-1288.

25. Kleinbaum DG, Kupper LL, Muller KE, Nizam A. Regression diagnostics. In: Applied Regression Analysis and Other Multivariable Methods. 3rd edition. Belmont, CA: Duxbury Press, 1998:237249.

26. Schectman JM, Bovbjerg VE, Voss JD. Predictors of medication-refill adherence in an indigent rural population. Med Care. 2002;40:1294-1300.

27. Serono. Serono Injectables Digest. 2nd edition. Rockland, MA: Serono; 2006.

28. Kotler P, Keller KL. Designing and managing integrated marketing channels. In: Marketing Management. 13th edition. Upper Saddle River, NJ: Prentice Hall, 2008:409-440. 